\title{
Intravenous volume replacement: which fluid and why?
}

\author{
Lucinda Huskisson
}

Fluids available for intravenous volume replacement may be either crystalloid or colloid. The fundamental differences between these fluids are their effects on the Starling equation (table 1) which describes fluid flux between the intravascular and interstitial spaces. Starling stated that the rate of fluid movement into or out of a capillary is related to the net hydrostatic pressure minus the net colloid osmotic pressure. ${ }^{1}$ The Starling equation has been modified to include coefficients which represent the permeability of the capillary membrane to small solutes $\left(\mathrm{K}_{\mathrm{fc}}\right)$ and its ability to prevent large molecules such as plasma proteins from crossing it $\left(\sigma_{c}\right){ }^{2}$ Colloids may be used to replenish the oncotic strength of the blood, thereby enhancing its water retaining capacity.

\section{Crystalloid versus colloid controversy}

Colloids are widely used in Europe for volume replacement, while crystalloids are the fluids of choice in many centres in the USA, ${ }^{3}$ but the relative merits of the two methods of management remain controversial. ${ }^{45}$

Workers in favour of colloids insist that the intravascular colloid osmotic pressure must be kept either above the capillary hydrostatic pressure or at least greater than $10 \mathrm{~mm} \mathrm{Hg}$ in critically ill patients to avoid a poor prognosis. ${ }^{6}$ Proponents of crystalloids maintain that colloids leak out of the capillaries, increasing interstitial colloid osmotic pressure which has a detrimental effect by increasing fluid flux out of the capillary. ${ }^{8}$ This is more likely to occur if $\sigma_{c}$ is reduced, as happens after burns, severe sepsis, and cardiopulmonary bypass.

Colloid solutions expand the intravascular space more effectively than crystalloids, with the same increase in cardiac output being achieved by smaller volumes and with less haemodilution. The crystalloid proponents argue that the interstitial space is depleted in conditions of hypovolaemia because of fluid shift into intravascular and intracellular compartments. ${ }^{10}$

Table 1 Starling equation

Nuffield Department of Paediatric Surgery Institute of Child Health, 30 Guilford Street, London WCIN 1EH Correspondence to: Miss Huskisson.
The interstitial space fills more readily after crystalloid resuscitation. Because of this, the volume of fluid required is two to three times greater than when using colloids, resulting in an increased risk of tissue oedema. Sponsors of the crystalloid school maintain that this is not harmful despite the fact that tissue oedema has been associated with tissue hypoxia and has been implicated in delayed healing of bowel anastomoses. ${ }^{11}$ Despite the increased volumes required, crystalloid resuscitation is cheaper than the colloid equivalent (table 2).

Velanovich analysed the mortality data from a number of clinical trials and concluded that after trauma, or in instances when the capillaries are likely to have increased permeability, resuscitation is best achieved with crystalloids. ${ }^{12}$ In other circumstances-such as during major elective surgery-mortality rates may be reduced by using colloids.

The most appropriate resuscitation regimens undoubtedly involve the use of both crystalloids and colloids. Criteria for volume administration include tachycardia, hypotension, low filling pressures, reduced urine output, metabolic acidosis and increasing core-peripheral temperature gradient, although it should be remembered that a child can maintain a normal heart rate and systemic blood pressure despite a $25 \%$ loss of circulating volume. Volume administration should not be based on reflex prescribing'He looks volume depleted, therefore give 10 $\mathrm{ml} / \mathrm{kg}$ of plasma'. An individual patient's fluid requirements should be based on the aetiology of the volume depletion, and the most appropriate fluids should be used in adequate volumes.

\section{Intravenous fluids available CRYSTALLOIDS}

(1) Dextrose

Because dextrose is rapidly metabolised after intravenous administration, $5 \%$ or $10 \%$ dextrose solutions act as free water, quickly equilibrating

Table 2 Cost of volume replacement by various agents

\begin{tabular}{lc}
\hline Fluid & Cost in £ per $500 \mathrm{ml}$ \\
\hline $4 \cdot 5 \%$ Albumin & $33 \cdot 00$ \\
$20 \%$ Albumin $(100 \mathrm{ml})$ & $(37.00)$ \\
Hespan & $16 \cdot 72$ \\
Pentaspan & $15 \cdot 70$ \\
Gelofusine & $3 \cdot 56$ \\
Haemaccel & $3 \cdot 81$ \\
Rheomacrodex & 6.51 \\
Macrodex & $4 \cdot 11$ \\
Normal saline & 0.78 \\
Hartmann's solution & 0.88 \\
\hline
\end{tabular}


Table 3 Chemical basis and source of clinically important colloids

\begin{tabular}{|c|c|c|c|c|}
\hline & Natural & $\begin{array}{l}\text { Hydroxyethyl } \\
\text { starches }\end{array}$ & Gelatins & Dextrans \\
\hline $\begin{array}{l}\text { Chemical basis } \\
\text { Source } \\
\text { Examples }\end{array}$ & $\begin{array}{l}\text { Protein } \\
\text { Blood } \\
\text { Albumin } \\
\text { FFP }\end{array}$ & $\begin{array}{l}\text { Carbohydrate } \\
\text { Amylopectin } \\
\text { Hespan } \\
\text { Pentastarch } \\
\text { Pentafraction }\end{array}$ & $\begin{array}{l}\text { Protein } \\
\text { Bovine collagen } \\
\text { Gelofusine } \\
\text { Haemaccel }\end{array}$ & $\begin{array}{l}\text { Carbohydrate } \\
\text { Bacterial synthesis } \\
\text { Dextran } 40 \\
\text { Dextran } 70\end{array}$ \\
\hline Excretion & $\begin{array}{l}\text { Liver/ } \\
\text { kidneys }\end{array}$ & $\begin{array}{l}\text { Amylase/RES/ } \\
\text { kidneys }\end{array}$ & $\begin{array}{l}\text { Kidneys } \\
\text { Proteases }\end{array}$ & \\
\hline
\end{tabular}

FFP, fresh frozen plasma; RES, reticuloendothelial system.

between the intracellular and extracellular fluid compartments. For every $100 \mathrm{ml}$ infused, only $7.5 \mathrm{ml}$ will remain in the intravascular space for a useful period of time, so dextrose solutions are inappropriate for intravascular fluid resuscitation.

\section{(2) Isotonic crystalloid solutions}

Isotonic crystalloids (for example, normal saline and Hartmann's solution) equilibrate rapidly throughout both the interstitial and intravascular spaces, so approximately one quarter of the administered volume will remain within the intravascular space.

\section{(3) Hypertonic saline solutions}

These have shown a resurgence of popularity. Small volumes of $7 \cdot 5 \%$ saline have successfully maintained the circulation after hypovolaemic shock. ${ }^{1314}$ Their role in paediatrics has not yet been assessed, and hypertonic saline may prove inappropriate for neonates with immature sodium handling. ${ }^{15}$

\section{COLLOID SOLUTIONS}

Colloid solutions, both natural (for example, human albumin solutions) and the synthetic macromolecules (for example, the gelatins, hydroxyethyl starches, and dextrans), theoretically remain within the intravascular space. Thus, volume for volume, they provide a greater and more sustained haemodynamic response than crystalloids. In the UK, standard paediatric practice is to use natural colloids for resuscitation. Although synthetic colloids are used sporadically, there has been a reluctance to use them routinely because of a lack of clinical trials concerning their use in children.

BASIC STRUCTURE OF COLLOIDS

The chemical basis and source of the clinically important colloids are shown in table 3 , and
Table 5 Molecular weight definitions

Weight average molecular weight $\left(M_{w}\right)$

$$
\mathbf{M}_{\mathbf{w}}=\frac{\text { sum of each molecule's weight }}{\text { total mixture's weight } \times \text { weight of the molecule }}
$$

Number average molecular weight $\left(M_{n}\right)$

$$
M_{n}=\frac{\text { mass of the sample in grams }}{\text { total number of chains }}
$$

After Hulse and Yacobi. ${ }^{18}$

table 4 summarises the pharmacology. The two molecular weights quoted for synthetic colloids are defined in table 5 . The weight average molecular weight $\left(M_{w}\right)$ determines the viscosity, while the number average molecular weight $(M$ ) gives an indication of the osmotic pressure exerted by the fluid. Albumin is monodispersethat is, all of the molecules within a solution are the same size and both $M_{w}$ and $M_{\text {are }} 69000$. All of the synthetic colloids are polydisperse, and have different values for $M_{w}$ and $M_{n}$ (table 4).

\section{PHARMACOLOGY OF INDIVIDUAL COLLOIDS}

Natural colloids

(A) Fresh frozen plasma-fresh frozen plasma is extracted from donated blood and because it is unpasteurised it has the potential to transmit blood borne infections. The Consensus Conference held at the National Institutes of Health has laid down strict guidelines for the administration of fresh frozen plasma, concluding that there is no justification for its use as a volume expander. ${ }^{19}$

(B) Albumin-Human albumin solution is derived from donated blood by fractionation and/or plasmapheresis. It is produced as a $4.5 \%$ solution (iso-oncotic with plasma) or as more concentrated (hyperoncotic) $10 \%$ or $20 \%$ solutions of 'salt poor' albumin. ${ }^{20}$

Albumin persists within the body for about 20 days, although its duration of action within the intravascular compartment varies from less than two hours to more than a day. ${ }^{21}$

Although freely donated, the processing of human albumin is expensive (table 2 ).

\section{Synthetic colloids}

(A) Gelatins-The gelatins tend to be considered as a homogeneous group but, because of different manufacturing processes, ${ }^{22}$ the individual solutions have differing properties, particularly in the incidence of adverse reactions. The new

\begin{tabular}{|c|c|c|c|c|c|c|c|}
\hline & Albumin & Gelofusine & Haemaccel & Hetastarch & Pentastarch & Dextran 40 & Dextran 70 \\
\hline $\begin{array}{l}M_{\mathrm{w}}(\mathrm{kDa}) \\
\mathbf{M}_{\mathrm{n}}(\mathrm{kDa}) \\
\text { Sodium }(\mathrm{mmol} / \mathrm{l}) \\
\text { Potassium }(\mathrm{mmol} / \mathrm{l}) \\
\text { Calcium }(\mathrm{mmol} / \mathrm{l})\end{array}$ & $\begin{array}{l}69 \\
69 \\
130-160 \\
1 \\
0\end{array}$ & $\begin{array}{l}30 \\
22 \cdot 5 \\
154 \\
<0 \cdot 4 \\
<0.4\end{array}$ & $\begin{array}{l}35 \\
24 \cdot 5 \\
145 \\
5 \cdot 1 \\
12 \cdot 5\end{array}$ & $\begin{array}{l}450 \\
71 \\
154 \\
0 \\
0\end{array}$ & $\begin{array}{l}200 \\
35 \\
154 \\
0 \\
0\end{array}$ & $\begin{array}{l}40 \\
25 \\
154 \\
0 \\
0\end{array}$ & $\begin{array}{l}70 \\
39 \\
154 \\
0 \\
0\end{array}$ \\
\hline $\begin{array}{l}\text { Duration of action } \\
\text { (hours) } \\
\text { Survival in body }\end{array}$ & 6 & $3-4$ & $3-4$ & $>8$ & $6-8$ & $3-4$ & $6-8$ \\
\hline $\begin{array}{l}\text { (days) } \\
\text { Water binding } \\
(\mathrm{ml} \mathrm{H}, \mathrm{O} / \mathrm{g} \text { colloid })\end{array}$ & 21 & $42 \cdot 8$ & $41 \cdot 7$ & $2-65$ & 30 & 37 & $28-42$ \\
\hline
\end{tabular}

Table 4 Characteristics of various colloids 101017 
generation gelatins are widely used within Europe. In the UK the two most commonly used solutions are: (1) Gelofusine (B Braun) which is a 'modified fluid' or succinylated gelatin and (2) Haemaccel (Hoechst) which is a polygeline, or urea-linked gelatin.

For intravascular volume expansion, they produce an effect which is almost equivalent to albumin, with a duration of action of three to four hours. In vitro evidence suggests that in conditions associated with capillary leak, Gelofusine may be more efficacious than albumin. ${ }^{23}$

(B) Hydroxyethyl starches (HES)_HES are derived from amylopectin which is stabilised by hydroxyethylation to prevent rapid hydrolysis by amylase. The HES solutions show a discrepancy between $M_{w}$ and $M_{\text {n }}$ (table 4 ) because they contain molecules with ${ }^{\mathrm{n}}$ a wide range of molecular weights, the smallest of which will be rapidly excreted by the kidneys, with the largest being taken up by macrophages of the reticulendothelial system. The greater the degree of substitution by hydroxyethyl groups, the more resistent the molecule is to breakdown by amylase and, therefore, the longer the survival within the body and the circulation.

Of the available HES solutions, the highest degree of substitution (seven hydroxyethyl groups per 10 of glucose) is seen in hetastarch (Hespan, Du Pont). Its intravascular effect may last up to 24 hours and its survival within the body is between two and more than 60 days. ${ }^{18} 2425$

Pentastarch (Pentaspan, Du Pont) has recently received a product licence in the UK. It has five groups per 10 of glucose. Although it still contains a large range of molecular sizes, it does not include molecules with a weight greater than a million daltons. This gives the compound the advantage of a shorter persistence within the body, but with a similar efficacy to hetastarch. ${ }^{2627}$

By diafiltering pentastarch, all of the molecules with a $M_{w}$ of less than 100000 daltons can be removed. This fluid (Pentafraction) is not commercially available, but preliminary animal work has suggested that its use may be associated with a reduction in capillary leak. ${ }^{9} 2829$

(C) Dextrans-Because of their high incidence of adverse effects, the dextrans are inappropriate for volume expansion in paediatrics. The two most commonly encountered dextrans are dextran 40 (for example, Rheomacrodex, Pharmacia) and dextran 70 (for example Macrodex, Pharmacia), the number representing the $M_{w}$.

\section{ADVERSE EFFECTS OF COLLOIDS \\ (1) Anaphylactoid reactions}

These have been reported with both natural ${ }^{30}$ and synthetic ${ }^{31}$ colloids. The reactions may be $\mathrm{mild} /$ moderate or severe as classified by Ring and Messmer, ${ }^{32}$ and the precise causes of the reactions remain unclear. Release of histamine by the gelatins has been suggested: firstly, because the incidence is higher with urea linked rather than succinylated gelatins $(0 \cdot 1 \%$ and
$0.05 \%$ respectively) and the former has been associated with free di-isocyanate, which causes histamine release; and secondly, the incidence of allergic reactions can be reduced by pretreatment with $\mathrm{H}_{1}$ and $\mathrm{H}_{2}$ blockers. ${ }^{33}$

The overall incidence of anaphylactoid reactions to HES is quoted at $0.08 \%$, the majority of which are mild, although severe reactions have been reported. ${ }^{34}$

The dextrans elicit the worst reactions, both in incidence and severity. These are mediated by dextran reactive antibodies which trigger the release of vasoactive mediators, ${ }^{33}$ and can be reduced by pretreatment with a hapten. The incidence of cardiac arrest associated with the dextrans, together with their adverse effects on haemostasis and interference with the cross matching of blood are the main factors in their unpopularity.

\section{(2) Coagulation effects}

Dilutional effects are seen with all the colloids (except fresh frozen plasma) but the polysaccharides have been associated with abnormalities of haemostasis which are more than simply dilutional. In particular, factor VIII concentrations may be appreciably reduced. ${ }^{35}$ Although in vitro tests may be altered by HES, the effects are rarely of clinical significance ${ }^{36-38}$ unless massive volumes are infused. ${ }^{39}$ The coagulation effects of the dextrans are more pronounced, and the dextrans are therefore used to reduce the incidence of postoperative venous thrombosis and fatal pulmonary embolism. ${ }^{40}$ As these complications are exceedingly rare in general paediatric surgery, they do not provide an indication for the use of dextrans in infants and children, although dextran 40 is used in the postoperative period after orthotopic liver transplantation in an attempt to reduce thrombotic complications in the anastomosed vessels. ${ }^{41}$

\section{(3) Risks of infection}

The albumin solutions used in the UK are prepared from donated blood which is screened for antibodies to certain blood borne diseases. Because recently infected donors may carry a virus against which antibodies may not yet have been raised, the potential for infection (for example, with HIV or the hepatitis viruses) remains should the pasteurisation process fail.

\section{(4) Interference with laboratory investigations} The polysaccharides may interfere with cross matching reactions and estimations of the erythrocyte sedimentation rate by 'coating' the red cells and causing their aggregation. The effects of HES can be reversed by washing the cells with saline. The effects of dextran are long lasting, which is a major disadvantage in patients requiring blood after dextran administration.

The dextrans have caused false positive glucose analysis results, ${ }^{42}$ and, together with Haemaccel, may interfere with the biuret determination of serum total protein. ${ }^{43}$ The gelatins 
migrate within the $\alpha_{2}$-fraction in electrophoresis, but do not appear to affect immunological assays. ${ }^{42}$

Amylase contributes to the elimination of HES from the body, and the serum amylase value may double after HES infusion. ${ }^{44}$

CLINICAL STUDIES WITH SYNTHETIC COLLOIDS There is a wealth of literature describing the adult experience with synthetic colloids, and a corresponding paucity of paediatric studies.

Boon has published his experience with Haemaccel over 14 years in more than 8000 patients, ${ }^{45}$ whilst Lundsgaard-Hansen and Tschirren ${ }^{46}$ have reported 20 years experience with Gelofusine. Both papers conclude that these two fluids are safe, effective, and worthwhile fluids for volume replacement. In critically ill patients, Gelofusine has been associated with increased oxygen consumpton. ${ }^{47}$

Six per cent HES was equal to albumin for peroperative volume replacement during paediatric anaesthesia. ${ }^{48}$ HES has been used satisfactorily in the pump prime for bloodless open heart surgery in children who are Jehovah's Witnesses. ${ }^{49}$ It has been studied extensively in adults with the conclusion that there is no difference between HES and albumin, with HES offering a considerable cost saving. ${ }^{36} 50-52$

Despite their unacceptable level of adverse effects, there is little doubt that the dextrans are very efficient plasma expanders. ${ }^{33} 53-55$

\section{PRESCRIBING PITFALLS}

(1) Serum albumin and measurement of colloid osmotic pressure

Under normal conditions, only half of the body's endogenous albumin is intravascular, but it contributes about $80 \%$ of the intravascular colloid osmotic pressure. ${ }^{56}$ In critically ill patients, because of the 'acute phase reaction', the serum albumin concentrations may not provide an accurate reflection of the colloid osmotic pressure as the production of acute phase proteins takes precedence over the synthesis of albumin. ${ }^{57}$ Albumin may be administered not because volume replacement is required, but because the serum albumin concentration is low.

\section{(2) Inadequate resuscitation}

Problems with crystalloid resuscitation are often related to inadequate volumes being administered, because the prescriber fails to allow for fluid movement into the interstitial compartment.

\section{(3) Volume overload}

While the gelatins are plasma substitutes, and can be used interchangeably with albumin, the dextrans and hydroxyethyl starches are true plasma expanders-that is, they produce an increase in plasma volume greater than the volume of colloid infused. Although this may be of clinical benefit, the risk of fluid overload and significant haemodilution is greater when administered by unwary prescribers.

\section{Conclusions}

Although there are certain indications for natural colloids-for example, after certain open heart operations when massive colloid infusion may be required, synthetic colloids could often be given in their place. Because of their safety, the gelatins (particularly the modified fluid gelatins) are the most appropriate choice but there are situations when the superior plasma expansion of hydroxyethyl starches may be required. Although studies with synthetic colloids in adult patients may be extrapolated to the paediatric population, there remains a need for an evaluation of synthetic colloids in paediatric practice.

1 Starling EH. On the absorption of fluids from the connective tissue spaces. 7 Physiol 1896;19:312-26.

2 Bevan DR. Colloid osmotic pressure. Anaesthesia 1980;35: 263-70.

3 Shoemaker WC. Hemodynamic and oxygen transport effects of crystalloids and colloids in critically ill patients. Curr Stud Hematol Blood Transfus 1986;53:155-76.

4 Laks H, O'Connor NE, Anderson W, et al. Crystalloid versus colloid hemodilution in man. Surg Gynecol Obstet 1976;142: 506-12.

5 Poole GV, Meredith JW, Pennell T, et al. Comparison of colloids and crystalloids in resuscitation from hemorrhagic shock. Surg Gynecol Obstet 1982;154:577-86.

6 Weil MH, Henning RJ, Morissette MP, et al. Relationship between colloid osmotic pressure and pulmonary artery wedge pressure in patients with acute cardiorespiratory failure. Am $\mathcal{F}$ Med 1978;64:643-50.

7 Falk JL, Rackow EC, Astiz M, et al. Fluid resuscitation in shock. Fournal of Cardiothoracic Anesthesia 1988;2 Suppl: 33-8.

8 Virgilio RW, Rice CL, Smith DE, et al. Crystalloid versus colloid resuscitation: is one better? A randomized clinical study. Surgery 1979;85:129-39.

9 Zikria BA, King TC, Stanford J, et al. A biophysical approach to capillary permeability. Surgery 1989;105: 625-31.

10 Ross AD, Angaran DM. Colloids versus crystalloids-a continuing controversy. Drug Intelligence and Clinical Pharmacy 1984;18:202-14.

11 Chan STF, Kapadia CR, Johnson AW, et al. Extracellular fluid volume expansion and third space sequestration at the fluid volume expansion and third space sequestration at the

12 Velanovich V. Crystalloid versus colloid fluid resuscitation: a elanovich V. Crystalloid versus colloid fluid resuscitation
meta-analysis of mortality. Surgery 1989;105:65-71.

13 de Felippe J, Timoner J, Velasco IT, et al. Treatment of refractory hypovolaemic shock by $7 \cdot 5 \%$ sodium chloride injections. Lancet 1980;ii:1002-4.

14 Vincent J-L. Fluids for resuscitation. Br f Anaesth 1991;67: 185-93.

15 Krummel TM, Lloyd DA, Rowe MI. The postoperative response of the term and preterm newborn infant to sodium administration. $\mathcal{F}$ Pediatr Surg 1985;20:803-9.

16 Klotz U, Kroemer H. Clinical pharmacokinetic considerations in the use of plasma expanders. Clin Pharmacokinet 1987;12:123-35.

17 Lutz $\mathrm{H}$, Georgieff $M$. Effects and side effects of colloid plasma substitutes as compared to albumin. Curr Stud plasma substitutes as compared to al

18 Hulse JD, Yacobi A. Hetastarch: an overview of the colloid and its metabolism. Drug Intelligence and Clinical Pharmacy and its metabolism

19 National Institutes of Health Fresh frozen plasma. Indications and risks. FAMA 1985;253:551-3.

20 McClelland DBL. Human albumin solutions. $B M 71990$; 300:35-7.

21 Lewis RT. Albumin: role and discriminative use in surgery. Can F Surg 1980;23:322-8.

22 Saddler JM, Horsey PJ. The new generation gelatins. A review of their history, manufacture and properties. Anaesthesia 1987:42:998-1004.

23 Webb AR, Barclay SA, Bennett ED. In vitro colloid osmotic pressure of commonly used plasma expanders and substitutes: a study of the diffusibility of colloid molecules. Intensive Care Med 1989;15:116-20.

24 Thompson W, Fukushima T, Rutherford RB. Intravascular persistence, tissue storage and excretion of hydroxyethyl starch. Surg Gynecol Obstet 1970;131:965-72.

25 Yacobi A, Stoll RG, Sum CY, et al. Pharmacokinetics of hydroxyethyl starch in normal subjects. F Clin Pharmacol 1982;22:206-12.

26 Mishler JM, Parry ES, Sutherland BA, et al. A clinical study of low molecular weight hydroxyethyl starch, a new plasma oxpander. Br f Clin Pharmacol 1979;7:619-22.

27 Waxman K, Holness R, Tominaga G, et al. Hemodynamic and oxygen transport effects of Pentastarch in burn and oxygen transport effects of Pe

28 Zikria BA. Subbarao C, O\% MC, et al. Macromolecules reduce abnormal microvascular permeability in rat limb 1306-9. 
29 Webb AR, Tighe D, Moss RF, et al. Advantages of a narrowrange, medium molecular weight hydroxyethyl starch for volume maintenance in a porcine model of fecal peritonitis. Crit Care Med 1991;19:409-16.

30 Ring J, Stephan W, Brendel W. Anaphylactoid reactions to infusions of plasma protein and human serum albumin. Clin Allergy 1979;9:89-97.

31 Ring J. Anaphylactoid reactions to plasma substitutes. Int Anesthesiol Clin 1985;23:67-95.

32 Ring J, Messmer K. Incidence and severity of anaphylactoid reactions to colloid volume substitutes. Lancet 1977;i:

33 Messmer K. Characteristics, effects and side-effects of plasma substitutes. In: Lowe KC, ed. Blood substitutes: preparation,
physiology and medical applications. Chichester: Ellis physiology and medical applications. Chich

34 Cullen MJ, Singer $M$. Severe anaphylactoid reaction to hydroxyethyl starch. Br $\mathcal{F}$ Anaesth 1990;45:1041-2.

35 Strauss RG. Review of the effects of hydroxyethyl starch on blood coagulation system. Transfusion 1981;21:299-302.

36 Munsch CM, MacIntyre E, Machin SJ, et al. Hydroxyethyl starch: an alternative to plasma for postoperative volume expansion after cardiac surgery. Br F Surg 1988;75:675-8.

37 Falk JL, Rackow EC, Astiz ME, et al. Effects of hetastarch and albumin on coagulation in patients with septic shock. f Clin Pharmacol 1988;28:412-5.

38 Gold MS, Russo J, Weinhouse G, et al. Comparison of hetastarch to albumin for perioperative bleeding in patients undergoing abdominal aortic aneurysm surgery. A prospective, randomised study. Ann Surg 1990;21:482-5.

39 Lockwood DNJ, Bullen C, Machin SJ. A severe coagulopathy following volume replacement with hydroxyethyl starch in following volume replacement with hydroxyethyl

40 Strauss RG. Volume replacement and coagulation: a comparative review. Foumal of Cardiothoracic Anaesthesia 1988; parative review.

41 Busuttil RW, Seu P, Millis JM, et al. Liver transplantation in children. Ann Surg 1991;213:48-57.

$42 \mathrm{Lutz} \mathrm{H}$, Georgieff $\mathrm{M}$. Effects and side effects of colloid plasma substitutes as compared to albumin. Cur Stud Hematol Blood Transfus 1986;53:145-54.

43 Weber JA, van Zanten AP. Interference of plasma expanders in the determination of total protein. Clin Chem 1989;35: 2143-4.
44 Condit D, Freeman K, Brodman R. Hyperamylasemia in cardiac surgical patients receiving hydroxyethyl starch. Fournal of Critical Care 1987;2:36-8.

45 Boon P. Clinical use of polygelatin. Dev Biol Stand 1981;48: 193-7.

46 Lundsgaard-Hansen P, Tschirren B. Clinical experience with 120,000 units of modified fluid gelatin. Dev Biol Stand 1981;48:251-6.

47 Edwards JD, Nightingale P, Wilkins RG, et al. Hemodynamic and oxygen transport response to modified fluid gelatin in and oxygen transport response to modified fluid ge

48 Hausdörfer J, Hagemann $\mathrm{H}$, Heine J. Comparison of plasma substitutes human albumin $5 \%$ and hydroxyethyl starch $6 \%$ $(40,000.0 .5)$ in paediatric anaesthesia. Anasth Intensivther Notfallmed 1986;21:137-42.

49 Kawaguchi A, Bergsland J, Subramanian S. Total bloodless open heart surgery in the pediatric age group. Circulation 1984;70 suppl 1:30-7.

50 Diehl JT, Lester JL III, Cosgrove DM. Clinical comparison of Hetastarch and albumin in postoperative cardiac patients. Ann Thor Surg 1982;34:674-9.

51 Kirklin JK, Lell WA, Kouchoukos NT. Hydroxyethyl starch versus albumin for colloid infusion following cardiopulmonary bypass in patients undergoing myocardial revascularization. Ann Thor Surg 1984;37:40-6.

52 Lumb PD. A comparison between $25 \%$ albumin and $6 \%$ hydroxyethyl starch on lung water accumulation during and immediately after cardiopumonary bypass. Ann Surg 1987;206:210-3.

53 Lamke L-O Liljedahl S-O. Plasma volume changes after infusion of various plasma expanders. Resuscitation 1976;5: 93-102.

54 Karanko MS. Effects of three colloid solutions on plasma volume and hemodynamics after coronary bypass surgery. Crit Care Med 1987;15:1015-22.

55 Stacca R, Bertellini E, Piccinini P, et al. Plasma expanders in hemorrhagic shock. Resuscitation 1989;18:153-4.

56 Grunert A. Colloid osmotic pressure and albumin metabolism during parenteral nutrition. Curr Stud Hematol Blood Transfus 1986;53:18-32.

57 Lundsgaard-Hansen P. Physiology and pathophysiology of colloid osmotic pressure and albumin metabolism. Cur Stud Hematol Blood Transfus 1986;53:1-17. 